\title{
Reticulócitos e hematócrito de cães pré e pós esplenectomia parcial
}

\author{
Reticulocytes and hematocrit of dogs before and after partial splenectomy \\ Sonia Terezinha dos Anjos Lopes ${ }^{1}$ Roberto Marinho Maciel ${ }^{2}$ Carina Franciscato $^{2}$ \\ Mauren Picada Emanuelli ${ }^{2}$ Rodrigo Siqueira Rivera ${ }^{3}$ Alexandre Mazzanti $^{4}$ \\ Luciele Varaschini Teixeira ${ }^{5}$
}

\section{RESUMO}

Os reticulócitos são células eritróides que exibem $R N A$ residual e são liberados da medula óssea em resposta à hipoxia tecidual. Após sua liberação da medula óssea, ficam temporariamente seqüestrados no baço, onde adquirem forma de eritrócitos maturos. Além disso, o baço também é responsável pelo armazenamento do sangue e seus elementos. A esplenectomia é indicada para casos de torção ou ruptura esplênica, esplenomegalia sintomática e massas esplênicas. Este estudo tem como objetivo avaliar a resposta dos reticulócitos e do hematócrito em cães submetidos à remoção parcial do baço. Para isso, foram utilizados nove cães, sem raça definida, machos e fêmeas. As coletas foram feitas uma hora antes e 48, 96, 144 e 168 horas após o procedimento cirúrgico. Os resultados demonstraram que o hematócrito diminuiu significativamente após a esplenectomia parcial. $O$ valor máximo de reticulócitos foi alcançado 96 horas após a cirurgia, a partir daí houve um declínio na quantidade de reticulócitos na corrente sangüínea, permanecendo, porém, em número superior à condição pré-esplenectomia parcial.

Palavras-chave: reticulócitos, esplenectomia parcial, hematócrito, cães.

\section{ABSTRACT}

The reticulocytes are erythroid cells that exhibit residual RNA, being released from bone marrow by erythropoietin stimulus in response to tissue hypoxia. After its release from bone marrow, they are temporarily sequestred in the spleen, where they acquire form of mature erythrocytes. Besides, the spleen is also responsible for storage of the blood and their elements. The splenectomy is indicated in cases of splenic torsion or rupture, symptomatic splenomegaly, and splenic masses. This study aimed to evaluate the response of reticulocytes and of hematocrit in dogs submitted to partial splenectomy. Nine mongrel males and female dogs were used. The samples were obtained one hour before the surgery and 48, 96, 144 and 168 hours after this procedure. The findings demonstrated that the hematocrit decreases significantly after the partial splenectomy. Highest values reticulocytes were reached $96 \mathrm{~h}$ after the surgery, followed by a decline in number, nevertheless, the counting was higher than moments before of the partial splenectomy.

Key words: reticulocytes, partial splenectomy, hematocrit, dogs.

Os reticulócitos são células eritróides que exibem RNA residual, que se precipitam ao entrar em contato com corantes, como o novo azul de metileno ou o azul cresil brilhante (RAPAPORT, 1990). Eles são metabolicamente mais ativos que eritrócitos maduros, possuindo quantidade de energia mais elevada em seu

\footnotetext{
${ }^{1}$ Departamento de Clínica de Pequenos Animais, Universidade Federal de Santa Maria (UFSM), 97105-900, Santa Maria, RS, Brasil. Email: sonia@smail.ufsm.br Autor para correspondência.

2 Programa de Pós-graduação em Medicina Veterinária da UFSM, Santa Maria, RS, Brasil.

${ }^{3}$ Curso de Medicina Veterinária, Universidade Federal do Paraná, Campus Palotina, Palotina, Paraná, Brasil.

${ }^{4}$ Departamento de Clínica de Pequenos Animais, UFSM, Santa Maria, RS, Brasil.

${ }^{5}$ Curso de Medicina Veterinária, UFSM, Santa Maria, RS, Brasil.
} 
interior e são liberados da medula óssea pela ação estimuladora da eritropoietina em resposta à hipoxia tecidual (FERNANDEZ \& GRINDEM, 2000).

Após serem liberados pela medula óssea, os reticulócitos ficam temporariamente seqüestrados na polpa vermelha do baço, onde adquirem forma e dimensões de eritrócitos maturos (COME et al., 1974), mas o estágio final da maturação ocorre na circulação sangüínea (PATEL et al., 1985). No cão adulto, são encontrados, normalmente, menos de $1 \%$ de reticulócitos, porém, em filhotes, o número alcança cerca de 7\% (JAIN, 1993).

A esplenectomia é indicada para torção e ruptura esplênica, esplenomegalia sintomática e massas esplênicas; sendo questionável para cães com distúrbios sangüíneos imunomediados (COUTO \& HAMMER 1997). Entretanto, a esplenectomia parcial é recomendável sempre que possível (LIPOWITZ \& BLUE, 1998).

Como o baço exerce função de remodelagem dos reticulócitos (COME et al., 1974), e também é responsável pelo armazenamento do sangue e seus elementos (POPE \& ROCHAT, 1996), o presente estudo tem como objetivo verificar se a remoção parcial deste órgão tem influência sobre a contagem de reticulócitos e sobre o hematócrito de cães.

Foram utilizados nove cães, adultos, sem raça definida, machos ou fêmeas, procedentes do biotério da Universidade Federal de Santa Maria. A cirurgia experimental foi realizada na aula prática da disciplina de Técnica Cirúrgica do curso de graduação em Medicina Veterinária. Uma hora antes da remoção de 50\% do baço, foi colhida uma amostra de sangue de cada animal para verificação do hematócrito e contagem de reticulócitos. Estes dados foram utilizados como controle e posteriormente comparados com os resultados pós-operatórios. Como medicação préanestésica, foi administrada acepromazina ${ }^{1}$ na dose de $0,05 \mathrm{mg} \mathrm{kg}^{-1}$ via intramuscular, e a anestesia feita com a associação de xilazina ${ }^{2}\left(1 \mathrm{mg} \mathrm{kg}^{-1}\right)$, cetamina ${ }^{3}\left(15 \mathrm{mg} \mathrm{kg}^{-1}\right)$ e atropina ${ }^{4}\left(0,044 \mathrm{mg} \mathrm{kg}^{-1}\right)$ via intramuscular. Após o ato cirúrgico, foram colhidas amostras sangüíneas em quatro momentos distintos e com intervalos de 48, 96, 144 e 168 horas. De cada animal, foram colhidos 3mL de sangue, utilizando-se o ácido etilenodiaminotetracético de sódio $^{5}$ (EDTA) como anticoagulante, na concentração de $10 \%$ e na proporção de $0,1 \mathrm{~mL}$ de EDTA para cada $5 \mathrm{~mL}$ de sangue.

O hematócrito foi determinado pela técnica do micro-hematócrito ${ }^{6}$ descrita por KERR (2003). A determinação do número de reticulócitos seguiu as recomendações de THRALL \& WEISER (1997), que preconiza a mistura de quantidades iguais de sangue e do corante novo azul de metileno ${ }^{7}$ na concentração de 5\%. A mistura permaneceu por 15 minutos em banhomaria $^{8}$ a $37^{\circ} \mathrm{C}$. Em seguida, foram feitos os esfregaços, para contagem dos reticulócitos presentes entre 1000 hemácias observadas na objetiva de imersão ${ }^{9} \mathrm{sob}$ aumento de 1000X. A percentagem de reticulócitos encontrada foi corrigida pelo grau de anemia, de acordo com a fórmula descrita por STOCKHAM \& SCOTT (2002), em que a percentagem de reticulócitos encontrada é multiplicada pelo resultado da razão entre o hematócrito do paciente e o hematócrito médio da espécie, no caso, estabelecido em 45\%.

Os dados obtidos foram submetidos à análise estatística, utilizando-se o teste de Dunnet, em que o momento da coleta pré-cirúrgica foi utilizado como padrão em relação aos demais momentos. O pacote estatístico utilizado foi o GraphPad In Stat. Os resultados com valores de $(\mathrm{P}<0,01)$ foram considerados significativos.

Neste estudo, observou-se diminuição significativa do hematócrito desde as 48 horas até 168 horas após a esplenectomia parcial (Tabela 1), semelhante com o que foi descrito por VOGEL et al. (2003) em ratos totalmente esplenectomizados. Segundo COUTO \& HAMMER (1997), a diminuição do hematócrito após a esplenectomia provavelmente se deva à remoção do reservatório esplênico de eritrócitos. Mesmo tendo sido realizada a retirada parcial do baço, evidenciou-se diminuição do hematócrito em todos os momentos pós-esplenectomia, sendo que esta diminuição chegou a até $16,5 \%$ no primeiro momento (48 horas) após a esplenectomia e, 168 horas após a cirurgia, o valor do hematócrito permanecia abaixo do valor pré-cirúrgico. COUTO \& HAMMER (1997) relataram que a diminuição média do hematócrito permaneceu pelo menos $15 \%$ abaixo dos valores de controle ao longo de seis meses posteriores à esplenectomia.

O número de reticulócitos apresentou um aumento significativo em 96 e 144 horas após a esplenectomia parcial destes cães (Tabela 1). PATEL et al. (1985) não observaram o aumento de reticulócitos circulantes após a esplenectomia de ratos, porém VOGEL et al. (2003) verificaram que o número de reticulócitos duplicou em ratos totalmente esplenectomizados. Para POPE \& ROCHAT (1996), a elevação do número de reticulócitos após a esplenectomia pode ser explicada pela liberação prematura destes na circulação geral, pela perda das funções de maturação do baço ou pelo retardo na maturação dos reticulócitos após a sua liberação na circulação. 
Tabela 1 - Valores médios, mínimos, máximos e desvios padrão para hematócrito (\%) e contagem corrigida de reticulócitos (\%) em momentos antes e após esplenectomia parcial em cães (n=9).

\begin{tabular}{ccc}
\hline Momentos de avaliação & Hematócrito (\%) & Contagem de reticulócitos (\%) \\
\hline \multirow{2}{*}{ 1h pré esplenectomia } & $43,7^{\mathrm{a}}$ & $0,33^{\mathrm{a}}$ \\
& $(35-46)$ & $(0,2-0,5)$ \\
& 4,24 & 0,16 \\
48h pós esplenectomia & $36,5^{\mathrm{b}}$ & $0,75^{\mathrm{a}}$ \\
& $(25-43)$ & $(0,7-1,8)$ \\
& 8,31 & 0,47 \\
96h pós esplenectomia & $37,1^{\mathrm{b}}$ & $2,14^{\mathrm{b}}$ \\
& $(26-38)$ & $(1,2-2,9)$ \\
& 7,03 & 1,33 \\
144h pós esplenectomia & $37,3^{\mathrm{b}}$ & $1,77^{\mathrm{b}}$ \\
& $(31-38)$ & $(2,2-2,2)$ \\
& 6,08 & 1,21 \\
168h pós esplenectomia & $38,0^{\mathrm{b}}$ & $1,13^{\mathrm{a}}$ \\
& $(33-39)$ & $(0,5-3,6)$ \\
\hline
\end{tabular}

Para letras iguais não há diferença significativa $(\mathrm{P}<0,01)$ em relação ao primeiro momento, de acordo com o teste de Dunnett.

No presente trabalho, foi constatado um aumento numérico, mas não significativo, na quantidade de reticulócitos 48 horas após a cirurgia, semelhante ao descrito por AIRD (2000) e FERNANDEZ \& GRINDEM (2000) em animais que tiveram grande perda sangüínea. No entanto, nesta pesquisa, o pico de aumento dos reticulócitos ocorreu 96 após o procedimento cirúrgico. Conforme explica JAIN (1993), após a intensificação da eritropoiese, os reticulócitos aumentam na circulação entre 72 e 96 horas após quadros hemorrágicos. Então, além da diminuição do espaço de maturação dos reticulócitos, pode-se atribuir o aumento destes à resposta da medula óssea à perda sangǘnea ocorrida na cirurgia de esplenectomia parcial, já que no interior do baço, há considerável depósito de hemácias (POPE \& ROCHAT, 1996). FERNANDEZ \& GRINDEM (2000) descreveram que o declínio dos reticulócitos circulantes ocorre gradualmente a partir de 2 a 3 semanas após perdas sangüíneas, porém, no presente estudo, verificou-se que, no final da primeira semana, já havia diminuição dos reticulócitos na circulação sangüínea, possivelmente devido à elevação na porcentagem do hematócrito que, mesmo não sendo significativa, já fez diminuir a condição de hipóxia tecidual, e a estimulação da medula óssea.

Conclui-se que a elevação máxima dos reticulócitos na corrente sangüínea ocorre quatro dias após a retirada parcial do baço. Porém, a recuperação do hematócrito requer um tempo maior, já que, em sete dias após a cirurgia, este ainda não havia retornado ao valor pré-cirúrgico.

\section{FONTES DE AQUISIÇÃO}

1.ACEPRAN 0,2\% - Univet S/A, São Paulo, Brasil. 2.COOPAZINE - Coopers Brasil Ltda, São Paulo, Brasil. 3.KETAMINA - Agener União Química Farmacéutica Nacional, São Paulo, Brasil.

4.ATROPINA 1\% CALBOS, Laboratórios Calbos Ltda, Curitiba, Brasil.

5.EDTA - LABSYNTH Produtos para Laboratórios LTDA. Diadema, Brasil.

6.Microhematócrito. Mícron Glass, São Paulo, Brasil.

7.Novo Azul de Metileno 5\%, Nova Derme, Santa Maria, Brasil. 8.Banho-maria $\left(37^{\circ} \mathrm{C}\right)$, DELEO, Porto Alegre, Brasil. 9.Microscópio óptico, OLYMPUS CH30, Japan.

Este trabalho foi realizado conforme as normas do Colégio Brasileiro de Experimentação Animal (www.cobea.org.br).

Ciência Rural, v.36, n.3, mai-jun, 2006. 


\section{REFERÊNCIAS}

AIRD, B. Clinical and hematologic manifestations of anemia. In: FELDMAN, B.F. et al. Schalm's veterinary hematology. 5.ed. Baltimore: Lippincott Williams \& Wilkins, 2000. Cap.24. p.140-142.

COME, S.E. et al. Surface remodeling vs. whole-cell hemolysis of reticulocytes produced with erythroid stimulation or iron deficiency anemia. Blood, v.44, n.6, p.817-830, 1974.

COUTO, C.G.; HAMMER, A.S. Afecções dos linfonódos e baço. In: ETTINGER, S.J.; FELDMAN, E.C. Tratado de medicina interna veterinária - moléstias do cão e do gato. 4.ed. São Paulo: Manole, 1997. V.2, cap.144, p.26672689.

FERNANDEZ, F.R.; GRINDEM, C.B. Reticulocyte response. In: FELDMAN, B.F. et al. Schalm's veterinary hematology. 5.ed. Baltimore: Lippincott Williams \& Wilkins, 2000. Cap.19, p.110-116.

JAIN, N.C. Essentials of veterinary hematology. Philadelphia: Lea \& Febiger, 1993. Cap.2. 417p.

KERR, M.G. Exames laboratoriais em medicina veterinária. 2.ed. São Paulo: Roca, 2003. Cap.17, p.339342 .
LIPOWITZ, A.J.; BLUE, J. Baço. In: SLATTER, D.H. Manual de cirurgia de pequenos animais. São Paulo: Manole, 1998. Cap.65, p.1143-1160.

PATEL, V.P. et al. Mammalian reticulocytes lose adhesion to fibronectin during maturation to erythocytes. Proc Natl Acad Sci USA, v.82, p.440-444, 1985.

POPE, E.R.; ROCHAT, M.C. Baço. In: BOJRAB, M.J. Mecanismos da moléstia na cirurgia de pequenos animais. São Paulo: Roca, 1996. Cap.89, p.722-728.

RAPAPORT, S.I. Hematologia introdução. 2.ed. São Paulo: Roca, 1990. Cap.2, 472p.

STOCKHAM, S.L.; SCOTT, M.A. Fundamentals of veterinary clinical pathology. Ames: Iowa State, 2002. Cap.2, p.42-46.

THRALL, M.A.; WEISER, M.G. Hematology. In: PRATT, P.W. Laboratory procedures for veterinary technicians. 3.ed. St. Louis: Mosby - Year Book, 1997. Cap.2, p.44-45.

VOGEL, J. et al. Transgenic mice overexpressing erythropoietin adapt to excessive erythrocytosis by regulation blood viscosity. Blood, v.102, n.6, p.2278-2284, 2003. 